\title{
GIS Database Template for Environmental Management of Mining in Indonesia
}

\author{
Sri Maryati ${ }^{1}$, Hideki Shimada ${ }^{1}$, Takashi Sasaoka ${ }^{1}$, Akihiro Hamanaka ${ }^{1}$, \\ Kikuo Matsui ${ }^{1}$, Hideaki Nagawa ${ }^{2}$ \\ ${ }^{1}$ Department of Earth Resources Engineering, Faculty of Engineering, Kyushu University, Fukuoka, Japan \\ ${ }^{2}$ Center of Urban Infrastructure, Environment and Resources, Fukuoka, Japan \\ Email: sri10r@mine.kyushu-u.ac.jp
}

Received October 1, 2011; revised November 25, 2011; accepted December 22, 2011

\begin{abstract}
Mining sector in Indonesia faces many challenges including needed to support national economy, compliance to central and local government regulations, local community empowerment and environmental impact management. Mining companies are mandatory to perform the environmental management efforts to minimize the negative impact to the environment and pursue sustainability of post-mining land use and as much as possible to restore land to the initial conditions. There are many challenges on management multi parameter and multi temporal spatial data of environmental management. The aim of this research is to design the GIS database template for environmental management in Indonesia's mining operation. This GIS database is designed using ArcCatalog ArcGIS 9.3 software, through following steps: inventory and assessment government regulations, inventory and assessment environmental quality standards, sorting and grouping parameters, design feature class and attribute, create GIS database, create GIS database dictionary. According to research result, GIS database template has many advantages for environmental management include integrated into a single database, avoid redundancy data, reduce volume data, uniformity data, easy to find and track data, integrated spatial and attribute data, can be used as an input for GIS analysis for decision-making and development strategies.
\end{abstract}

Keywords: GIS; Spatial Database; Mining; Environmental Management

\section{Introduction}

Mining sector gives various contributions to Indonesia's national economy; it contributed significantly to Indonesian gross domestic product (GDP). Indonesia's mining sector faces many challenges including needed to support national economy, compliance to central and local government regulations, local community empowerment and environmental impact management.

As known, mining is a temporary land use for exploration and exploitation of the coal and mineral reserves from the earth. There are several impacts to the environment if not managed properly. The Impacts include physical landscape changes/disturbance, water pollution, ground water contamination, air pollution, noise, soil erosion, sedimentation, destruction of biodiversity, destruction of water biota, and land degradation.

Mining in Indonesia should be managed properly to achieve sustainable development in line with the mandate of The 1945 Constitution of the Republic of Indonesia article 33 "The national economy shall be conducted based on economic democracy upholding the principles of togetherness, efficiency with justice, continuity, environ- mental perspective, self-sufficiency, and keeping a balance in the progress and unity of the national economy" [1].

To overcome the environmental problems that may result from mining activities, The Government of Indonesia has issued several regulations including Law of the Republic of Indonesia number 32 of 2009 concerning Environmental Protection and Management; Decree of the Minister of Mines and Energy number 1211.k/008/ M.PE/1995 concerning the Prevention and Remedy of Environmental Damage and Environmental Pollution in Business Activity of General Mining; Decree of the Minister of Mines and Energy number 1453.k/29/MEM/2000 concerning Technical Guidelines on Government Duties in General Mining; State Minister of Environmental Regulation No. 08 Year of 2006 concerning Guidance for Arranging Environmental Impact Assessment [2-5].

The regulations are basically mandate mining companies to maintain environmental sustainability; minimize environmental impact; comply with the environmental quality standards; provide regular, up to date and accurate report related to management and monitoring environmental aspect; provide reclamation plan and post-mining 
plan; provide map related to management and monitoring of environmental parameters.

Management and monitoring environmental parameters in mining operation deals with collecting, storing, analyzing, displaying and presenting multi parameter and multi temporal spatial data. There are many challenges on management multi parameter and multi temporal environmental spatial data. Geographic information system (GIS) database has a great potential to face the challenges.

GIS contribution in environmental monitoring is very important and very useful for managing data routinely from field measurement [6]. GIS is also an accurate, effective and efficient tool which has the capability on building, managing and analyzing spatial data [7]. Spatial database along with the attribute data can be used as an input for GIS for further analysis to deduce result which can be used for decision-making and development strategies [8].

The aim of this research is to design the GIS database template for environmental management in Indonesia's mining operation. It is expected that environmental databases from mining companies have uniformity in data collection procedure, field measurement procedure, results classification, coding and data management, analysis method, and reporting data system to the environmental agency.

\section{Indonesia Government Regulations}

Law of the Republic of Indonesia number 32 of 2009 concerning Environmental Protection and Management, is prepared based on facts that development activities have the risk to generate pollution and environmental damage that can lead the reduction of carrying capacity, productivity and capacity of the environment. Obligation to provide correctly, accurately, open and regularly information related to the environmental protection and management; maintain the sustainability of the environment, and comply with the environmental quality standards and or standard criteria of environmental damage is written in article 67 [2].

Decree of the Minister of Mines and Energy number 1211.k/008/M.PE/1995 concerning the Prevention and Remedy of Environmental Damage and Environmental Pollution in Business Activity of General Mining, obliges mining company to submit annual environmental management plan include land use plan, techniques and methods of environmental management, schedule of work and completion of reclamation phase, the area to be reclaimed, the crop type to be planted and environmental management estimation cost. Mining companies are also obliged to submit annual environmental monitoring plan include environmental parameters to be monitored, location of monitoring point, frequency of monitoring, and monitoring estimation cost. Article 14 clearly states that chief operating officer is required to provide map related to environmental management and monitoring [3].

Decree of the Minister of Mines and Energy number 1453.k/29/MEM/2000 concerning Technical Guidelines on Government Duties in General Mining; explain in detail the annual environmental management plan and environmental monitoring plan [4].

\section{Methodology}

GIS database template is built using ArcCatalog ArcGIS 9.3 software. As represented in Figure 1, the GIS database template is built using following step: inventory and assessment government regulations; inventory and assessment environmental quality standards; sorting and grouping parameters; design feature class and attribute; create GIS database; create GIS database dictionary. Each Step will be explained in detail in the subsequent chapter.

\subsection{Inventory and Assessment Government Regulations}

Environmental management and monitoring in mining operations should be conducted in accordance with the related government regulations including:

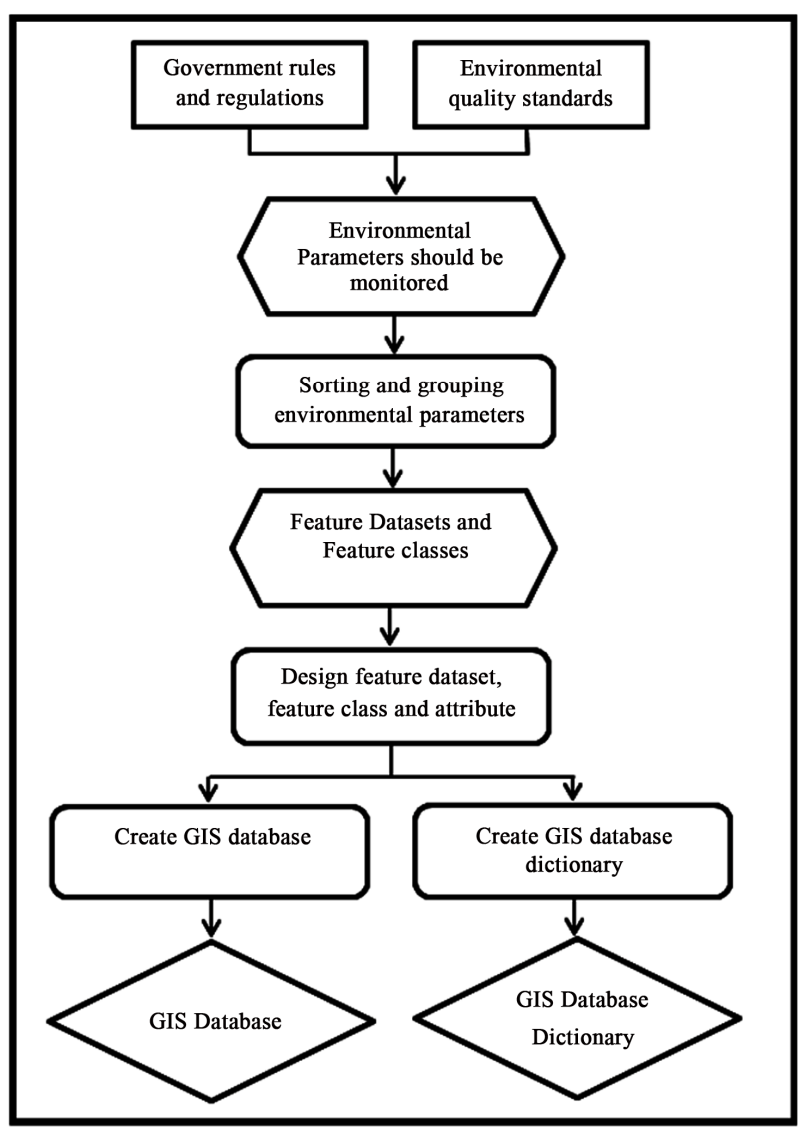

Figure 1. Flowchart GIS database template development. 
1) Law of the Republic of Indonesia number 32 of 2009 concerning Environmental Protection and Management [2];

2) Decree of the Minister of Mines and Energy number 1211.k/008/M.PE/ concerning the Prevention and Remedy of Environmental Damage and Environmental Pollution in Business Activity of General Mining [3];

3) Decree of the Minister of Mines and Energy number 1453.k/29/MEM/2000 concerning Technical Guidelines on Government Duties in General Mining [4];

As a result of inventory and assessment to those government regulations, the environmental parameters should be monitored include:

- Land cleared area

- Reclaimed area

- Land clearing plan

- Land reclamation plan

- After mined land

- Dumping soil area

- Dumping over burden area

- Re-vegetation area

- Flora and fauna

- Water quality

- Solid waste

- Chemical waste

- Air quality

- Soil

- Slope stability

- Erosion

- Landscape change

- Aquatic habitat

\subsection{Inventory and Assessment Environmental Quality Standards}

Environmental management and monitoring in mining operations should be complied with the related environmental quality standards including:

1) Government regulation No 41/1999 on air pollution control [9];

2) Decree of the State Minister of Environment No 48 of 1996 on emission standards for noise level [10];

3) Decree of the State Minister of Environment No 49 of 1996 on standards for vibration level [11];

4) Decree of the State Minister of Environment No 13 of 1995 on emission standards for stationary source [12];

5) Decree of the State Minister of Environment No 113 of 2003, waste water standard for coal mining [13].

As a result of inventory and assessment to those environmental standards, the environmental parameters should be monitored include:

- Ambient air quality standard (Sulfur Dioxide, Carbon Monoxide, Nitrogen Dioxide, Oxidant, Hydro Carbon, Particulate Matter < $10 \mu \mathrm{m}$, Particulate Matter $<2.5 \mu \mathrm{m}$, Total Suspended Particle, Plum- bum (Pb), Dust fall, Total Fluorides, Fluor Index, Chlorine and Chlorine Dioxide, Sulphat Index)

- Air vibration

- Noise

- Water quality (pH, Total suspended residue, Fe Total and Mn Total)

\subsection{Sorting and Grouping Parameters}

There are 46 environmental parameters should be monitored. Those parameters should be grouped into feature datasets. Parameters which have the same characteristic and belong to a specific theme were grouped and organized into one feature dataset.

As stated by MCRMP 2005 "The grouping is not based on feature data type and attributes fields and it combines feature that logically belong together" [14]. As can be seen in Figure 2, there are seven datasets including base map dataset, land use dataset, air quality dataset, water quality dataset, waste monitoring dataset, reclamation dataset, and biology dataset.

\subsection{Design Feature Class and Attribute}

Design feature class and attribute is the most important step in the building of the template databases because this step will determine what the database will look like. This step includes determination of feature class name, determination of coordinate system, determination of data type, determination of field name and field properties, determination of code for each environment parameters, creating reference tables.

Feature class name is determined according to the geographic features to allow users to easily recognize the feature class. The coordinate system chosen for this GIS database is the "Geographic Coordinate System-World Geodetic System 1984”/GCS WGS 1984.

Feature class can be represented as point, line and polygon. For example, administration boundary is displayed as polygon, river and mine road are displayed as line and rainfall station is displayed as point. Field name and field properties are determined according to the information should be included in feature class attribute.

\subsection{Create GIS Database}

GIS database in ArcCatalog is collection of feature datasets and a feature datasets is a group of feature classes. This step includes create personal geodatabase, create feature dataset, create feature class, determine the feature class properties.

As shown in Figure 3, the personal geodatabase is labeled as Environmental Monitoring and Management Geodatabase. This geodatabase contains seven feature datasets. 


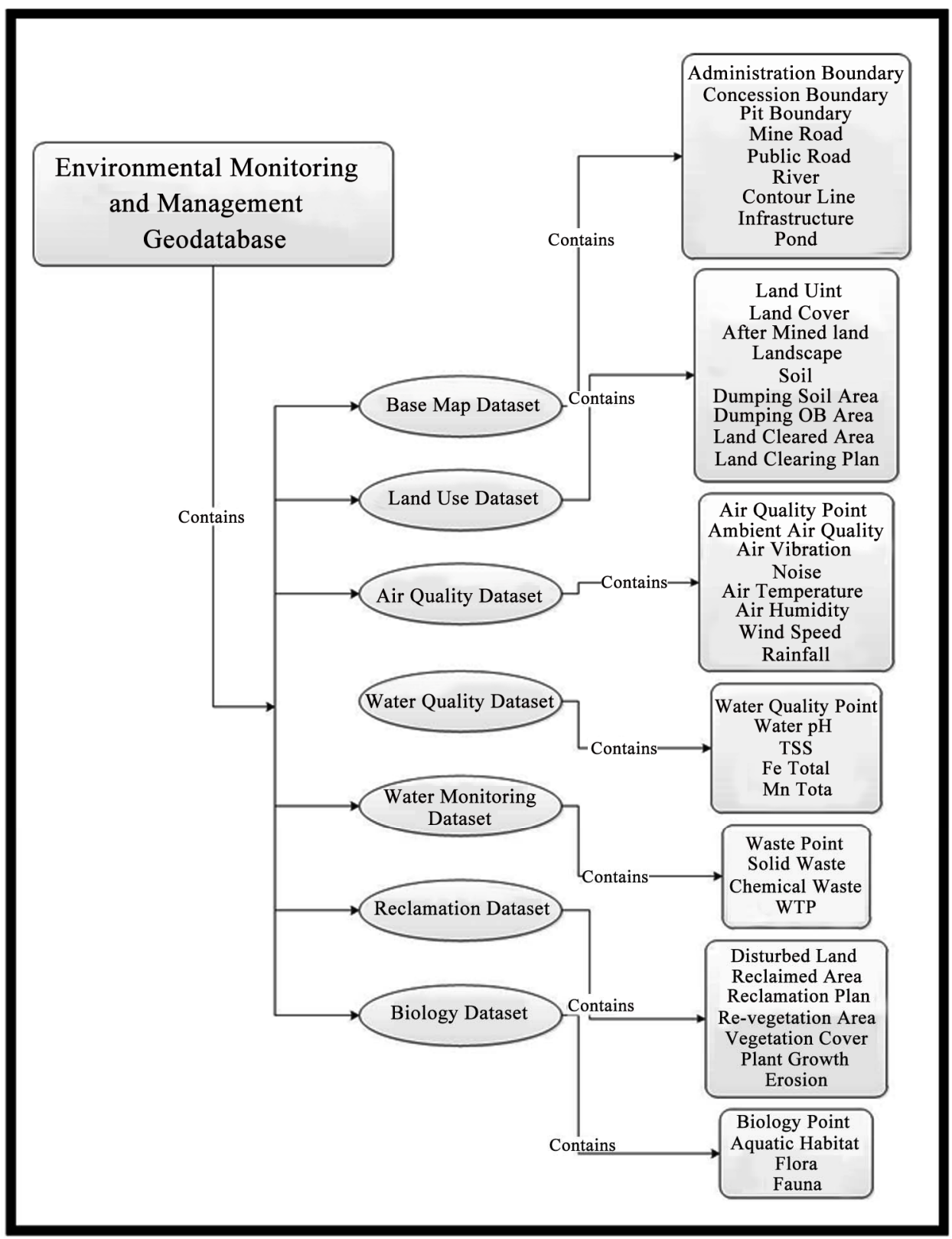

Figure 2. Structure of the environmental monitoring and management geodatabase.

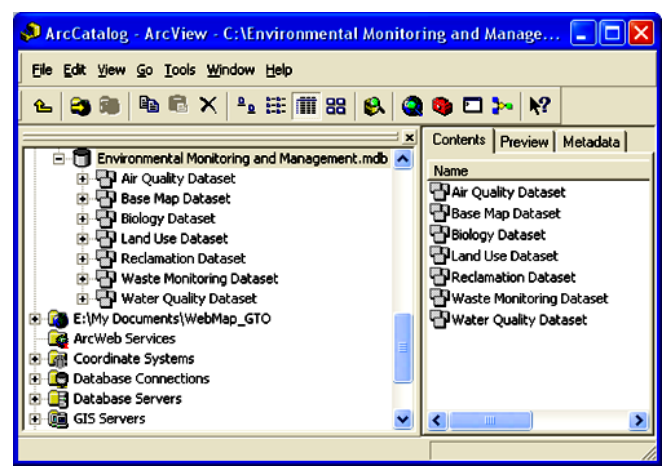

Figure 3. Environmental monitoring and management geodatabase.
Feature dataset is a group of feature classes that have same coordinates system and logically belong to a specific theme. As can be seen in Figure 4, the base map dataset contains nine feature classes that will be used as the base map for thematic maps in mining operation mapping.

The feature class properties provide information regarding field properties, coordinate system, tolerance, resolution, domain indexes, subtypes, relationship and representation. All information about the spatial data is stored in the field's attribute. As shown in Figure 5, the field properties include the field name, data type, alias, allow null values, default value, and length. 


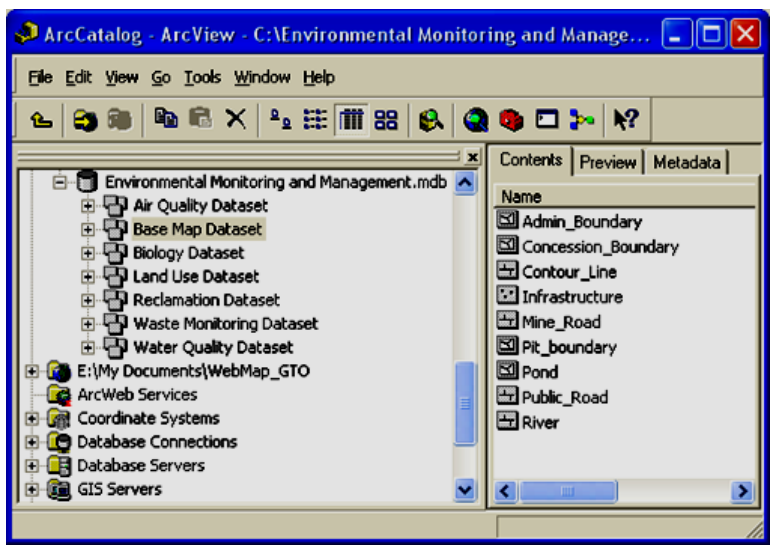

Figure 4. Feature classes of base map dataset.

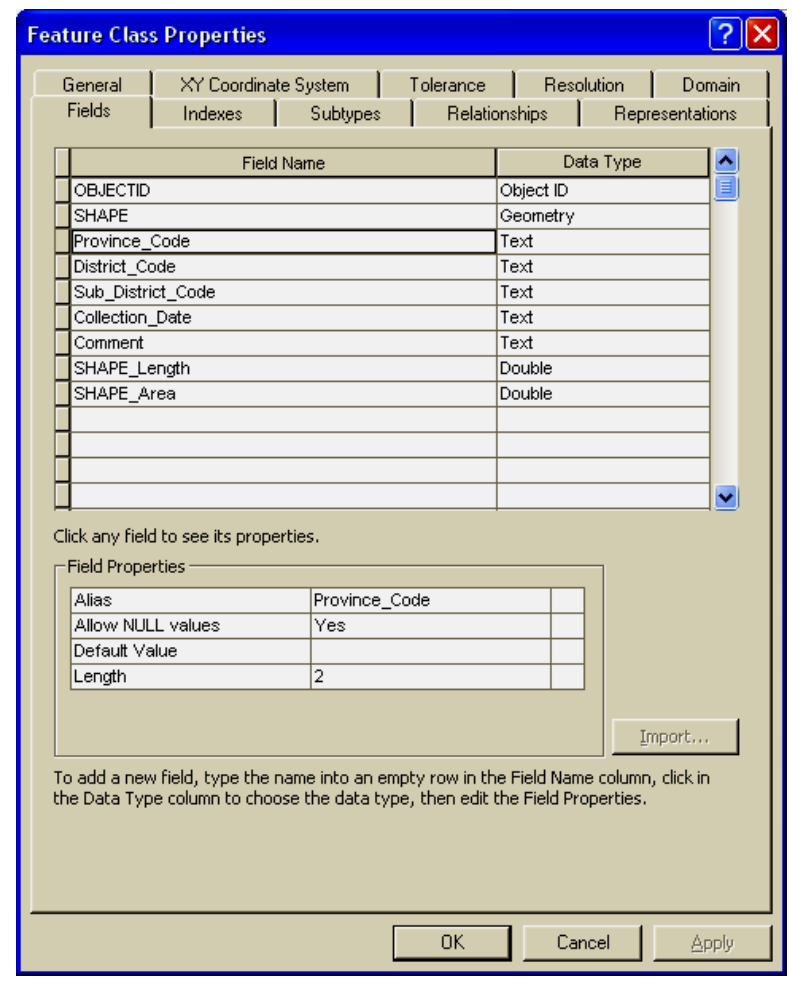

Figure 5. Feature class properties.

\subsection{Create GIS Database Dictionary}

GIS database dictionary acts as a communication tool for designer, operator, analyst, field surveyor and user so this dictionary must describe a whole database in detail. The dictionary as can be seen in Figure 6, describes data definition, data type, coordinate system, feature class field properties, relationship diagram and reference table.

The data dictionary is useful for various parties involved in environmental monitoring and management of mining operation including field surveyor for field measurement, GIS operator for input the attribute data, GIS analyst for processing and data analysis, map users and decision maker.

\section{Discussion}

\subsection{Base Map Dataset}

The base map dataset contains feature classes to be used as a base map for thematic maps. This dataset includes administration boundary, concession boundary, pit boundary, mine road, public road, river, contour line, infrastructure and pond. Figure 7 illustrates the design of base map dataset.

\begin{tabular}{|c|c|c|c|c|}
\hline \multicolumn{5}{|c|}{ MINE ROAD } \\
\hline $\begin{array}{l}\text { Definition }: \\
\text { Data type } \\
\text { Coordinate System : }\end{array}$ & \multicolumn{4}{|c|}{$\begin{array}{l}\text { Roads in mining areas for the passage of vehicles and } \\
\text { heavy equipment used in mining operations } \\
\text { Line } \\
\text { GCS WGS } 1984\end{array}$} \\
\hline \multicolumn{5}{|c|}{ Feature class field properties } \\
\hline Field Name & Type & \multirow[t]{2}{*}{ Length } & \multicolumn{2}{|c|}{ Remark } \\
\hline Road ID & Object ID & & & \\
\hline Shape & Geometry & & \multicolumn{2}{|c|}{ Filled automatically by GIS } \\
\hline Surface Type & Text & 6 & \multicolumn{2}{|c|}{ Refer to Surface Type Code } \\
\hline Condition & Text & 5 & \multicolumn{2}{|c|}{ Refer to Condition Code } \\
\hline Road Name & Text & 40 & \multicolumn{2}{|l|}{ Fill the Road Name } \\
\hline Pit ID & Text & 3 & & \\
\hline \begin{tabular}{|l|} 
Collection Date \\
\end{tabular} & Text & 8 & \multicolumn{2}{|l|}{ Yyyymmdd } \\
\hline Comment & Text & 40 & \multicolumn{2}{|c|}{ Fill the other important information } \\
\hline SHAPE_length & Double & & Calculated autom & by GIS \\
\hline & & lationsh & ip Diagram & \\
\hline Road ID & & & Filled automati & y GIS \\
\hline Shape & & & & \\
\hline Surface type & Text (6) & & Refer to Surface $T$ & \\
\hline Condition & Text (5) & & & \\
\hline Roaf Name & Text (40) & & Rete & lition Code \\
\hline Pit ID & Text (3) & & Kere & Fondition Code \\
\hline Collection data & $\mathrm{N}(9)$ & & & \\
\hline Comment & $C(40)$ & & & \\
\hline SHAPE_length & Double & & Calculated automa & by GIS \\
\hline & & Referen & Table & \\
\hline Surface Typ & pe Code & & Condition Typ & \\
\hline Code & Descri & tion & Code & Description \\
\hline Road01 & Stone $\mathrm{F}$ & aved & RoadG & Good \\
\hline Road02 & Brick $\mathrm{F}$ & aved & RoadF & Fair \\
\hline Road03 & Unpa & & RoadP & Poor \\
\hline
\end{tabular}

Figure 6. Mine road data dictionary.

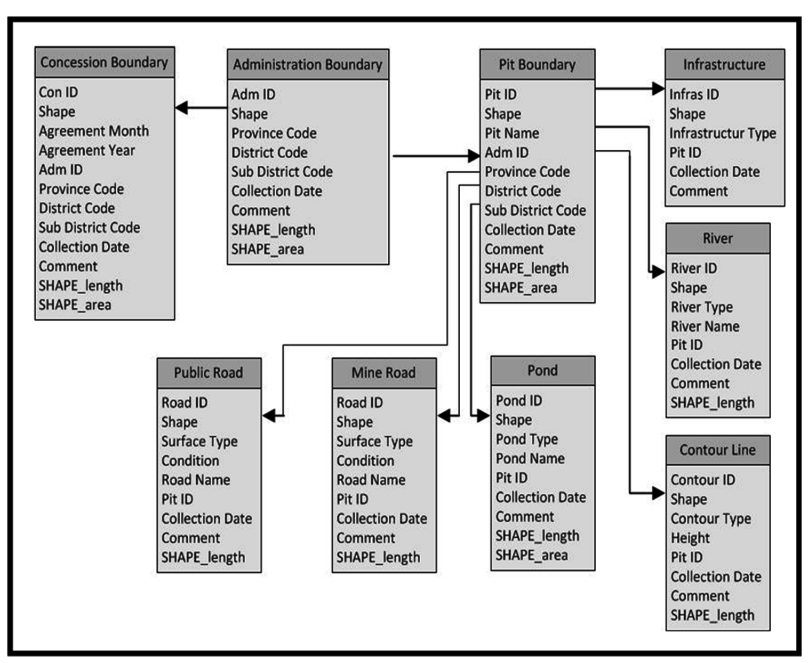

Figure 7. The design of base map dataset. 
Codes used in the base map dataset refer to various sources. Province code, district code, sub district code refers to Statistics Indonesia's codes. Surface code, condition code, river type code, contour type code, infrastructure type code and pond type code is compiled based on conditions typically found in the mining field.

\subsection{Water Quality Dataset}

The water quality dataset mainly contains feature classes related to water quality parameters required by regulations to be monitored. This dataset contains five feature class include water quality point, water $\mathrm{pH}$, TSS (total suspended sediment), Fe Total and Mn Total. Figure 8 illustrates the conceptual design of water quality dataset. In this dataset, the field attributes related to field measurement results is not filled in using specific code but filled with real results of field measurements.

\subsection{Air Quality Dataset}

The air quality dataset contains feature classes related to air parameter measurement both air quality condition and also weather condition. This dataset includes air quality point, ambient air quality, air vibration, noise, air temperature, air humidity, wind speed and rainfall. Figure 9 illustrates the air quality dataset design.

Similar to water quality dataset, the field attributes related field measurement results is filled with real results of field measurements.

\subsection{Waste Monitoring Dataset}

The waste monitoring dataset contains feature classes related to monitoring waste generated during the mining operation. This dataset includes waste point, solid waste, chemical waste, WTP (waste treatment plant). Figure 10 illustrates the waste monitoring dataset design. Each feature class contains information include point monitoring name, latitude-longitude position and field check result.

\subsection{Land Use Dataset}

The land use dataset mainly contains feature classes related to land utilization. This dataset contains nine feature class includes land unit, land cover, after mined land, landscape, soil, dumping soil area, dumping over burden area, land cleared and land clearing plan. Figure 11 illustrates the conceptual design of land use dataset. Codes used in the land use dataset refer to government regulations, general soil type in Indonesia, and based on conditions typically found in the mining field.

\subsection{Biology Dataset}

The biology dataset mainly contains feature classes related to flora, fauna and biodiversity monitoring. This da- taset contains four feature class includes biology point, aquatic habitat, flora and fauna. Figure 12 illustrates the

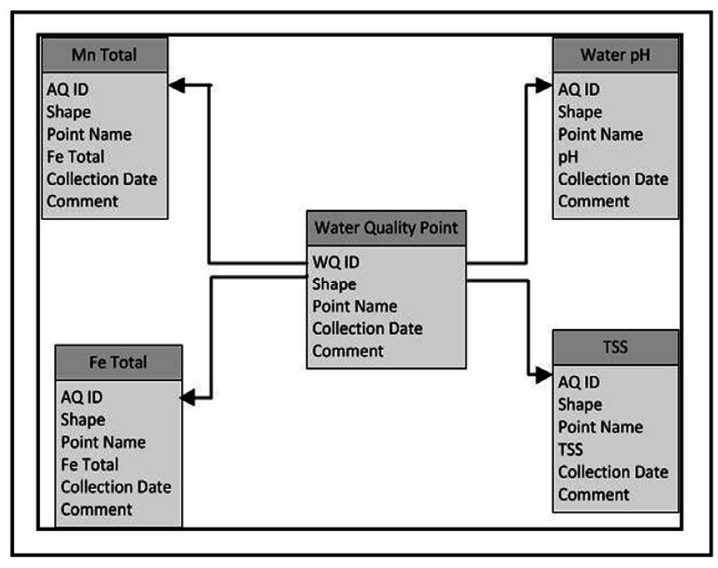

Figure 8. The design of water quality dataset.

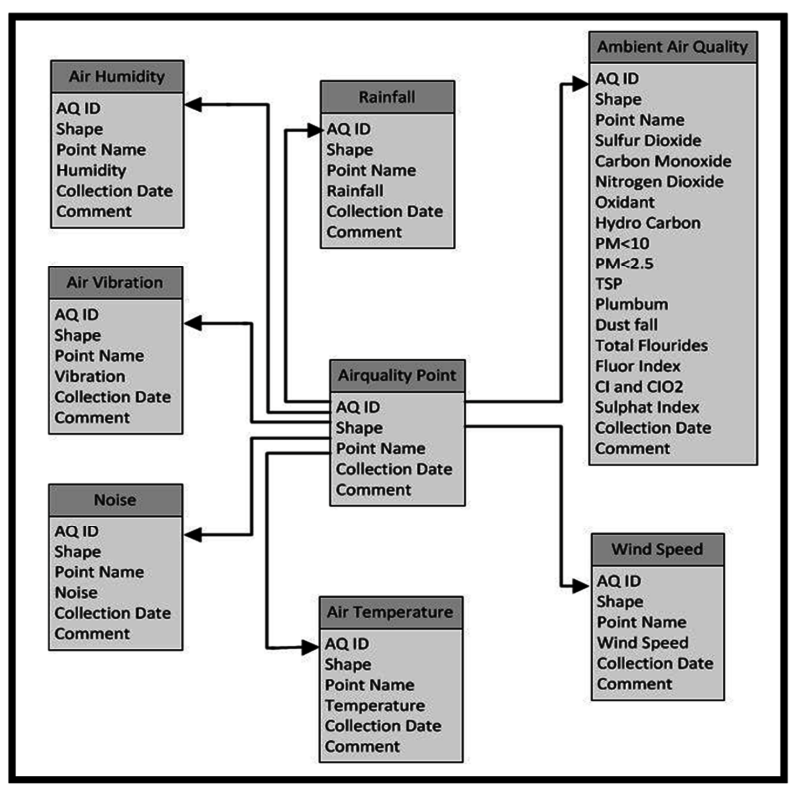

Figure 9. The design of air quality dataset.

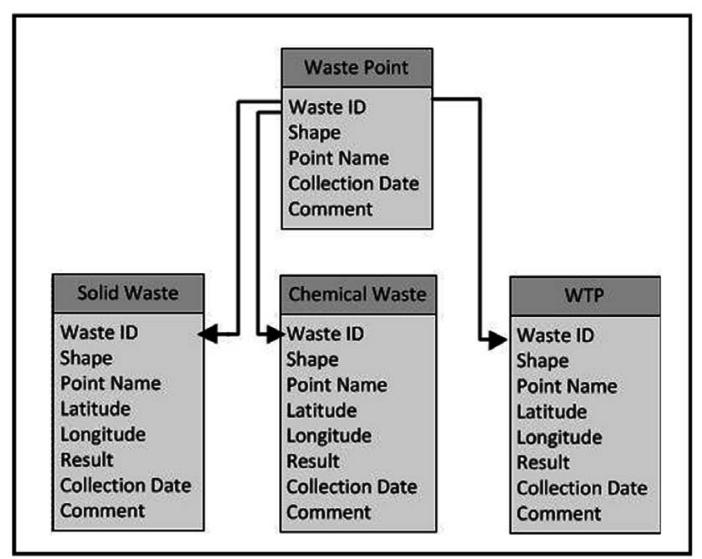

Figure 10. The design of waste monitoring dataset. 


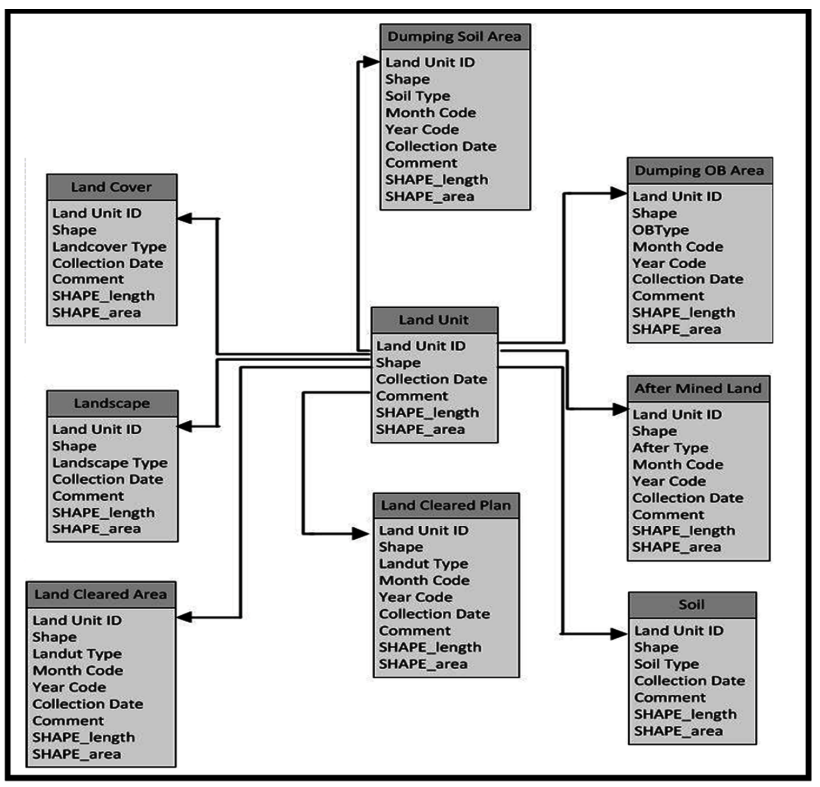

Figure 11. The design of land use dataset.

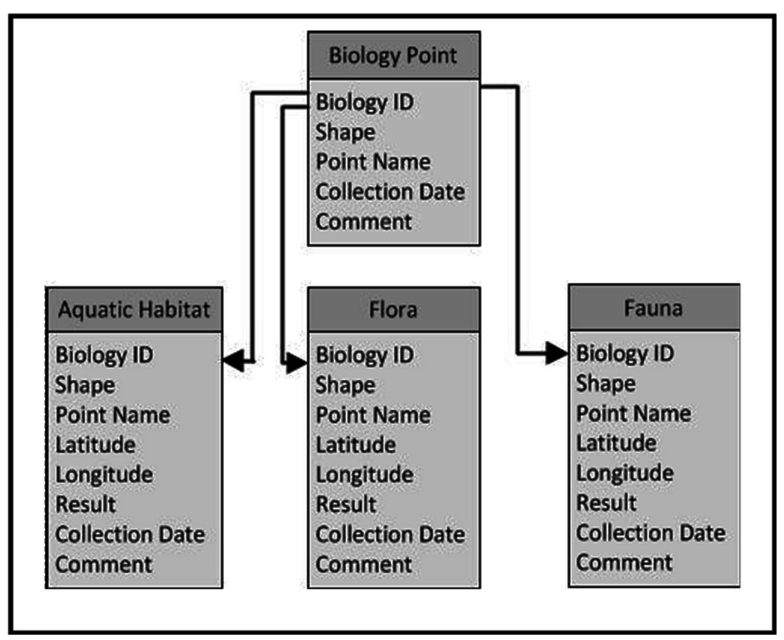

Figure 12. The design of biology dataset.

conceptual design of biology dataset. Each feature class contains information regarding point monitoring name, latitude-longitude position and field check result.

\subsection{Reclamation Dataset}

The reclamation dataset contains feature classes related to reclamation activities. As can be seen in Figure 13, this dataset includes disturbed land, reclaimed area, reclamation plan, re-vegetation area, vegetation cover, plant growth and erosion.

Refers to Decree of the Minister of Mines and Energy number 1453.k/29/MEM/2000 concerning Technical Guidelines on Government Duties in General Mining [4], reclaimed area and reclamation plan data should contain information related to land utilization type after reclama- tion. Re-vegetation area feature class should contain information include crop type, month and year of planting. Vegetation cover feature class should contain the percentage of vegetation cover. This data can be collected from field check measurement and also can be collected using remote sensing satellite. To monitor the success of reclamation is need information regarding plant growth and it can vary from very good, good, fair, disturbed. Erosion feature class should contain erosion type and erosion rate.

\subsection{Advantages and Challenges}

Mining companies in Indonesia are mandatory to perform the environmental management efforts to minimize the negative impact and pursue sustainability of post-mining land use and as much as possible to restore land to the initial conditions.

GIS database template for environmental management of mining should be able to accommodate various types of mining and also mine sites spread over several islands in Indonesia. GIS database template for environmental management of mining should be designed refers to related law, government regulation, minister decree and environmental quality standard.

Trial for GIS database has been carried out using the following steps: collecting data related to environmental management, examining and choosing the best and newest data, converting data format, converting coordinate system, editing and filling data attribute refers to data dictionary, loading data into database.

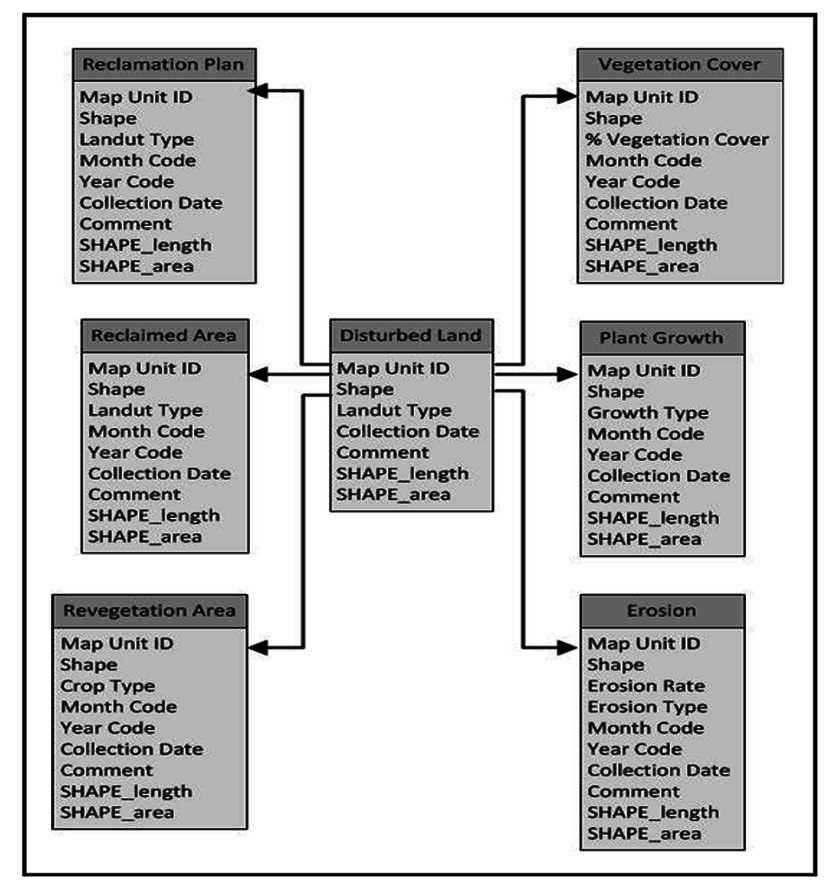

Figure 13. The design of reclamation dataset. 
Collecting data related to environmental management is time consuming because the data is stored in many folders, spread over several computers, and there is no standard file name so making it difficult to identify and recognize the data. Examining and choosing the best and newest data is necessary because there are many versions of data and there is no information or history about the collection date. It is necessary to convert various data format to shape file (*.shp) to enables loading data into database. Converting coordinate system is carried out from local coordinate to geographic coordinate system WGS 1984. Filling data attribute is carried out refers to data dictionary. Loading data into database is very easy, it needs user to specify which fields in the input data are loaded into the database.

According to the trial result, there are many advantages on managing the environmental management data using GIS spatial database. The advantages include all spatial data is managed into a single database; avoid redundancy data; reduce volume data; consistency data, uniformity on feature class name, codes for each parameter, coordinate system and data type; easy to find data; easy to track data because history data and collection date is recorded on the data; integrated management of spatial data and attribute data; completed with data dictionary; can be used as an input for GIS analysis for decision-making and development strategies.

The usage of GIS database for environmental management and monitoring of mining operations include monitoring reclamation, monitoring land cover change, monitoring water quality, monitoring air quality, monitoring biodiversity, monitoring erosion, and monitoring landscape changes.

On other hand there are several challenges to implement GIS spatial database in environmental management, it include introducing and training of GIS database to all data users; editing and updating data refers to the data dictionary include data format, coordinate system and field attribute; cost for purchasing software. This GIS spatial database template should be dynamic, which can be updated if there are changes in government regulations or there are additional needs for mining operation.

\section{Conclusions}

This paper described the development of GIS database template for environmental management of Mining in Indonesia. The GIS database template is designed and built to support mining companies in Indonesia in environmental management. According to GIS database template trial, it has shown promising results for environmental management of mining operation. Using the GIS spatial database template for environmental management of mining has many advantages; however there are also several challenges to implement it.

\section{Acknowledgements}

The authors' greatly acknowledge the Global-Center of Excellence in Novel Carbon Resource Sciences, Kyushu University, Japan for financial support. The authors' wish to express their deepest gratitude to PT. Kaltim Prima Coal, Indonesia for the research internship permit and to the Center of Urban Infrastructure, Environment and Resources, Fukuoka, Japan for the continuous support.

\section{REFERENCES}

[1] The Republic of Indonesia, “The 1945 Convention,” Jakarta, 2002.

[2] The Republic of Indonesia, "Law of the Republic of Indonesia Number 32 of 2009, Concerning Environmental Protection and Management, State Gazette of the Republic of Indonesia Number 140 of 2009," State Secretariat of the Republic of Indonesia, Jakarta, 2009.

[3] The Republic of Indonesia, "Decree of the Minister of Mines and Energy number 1211.k/008/M.PE/ 1995 Concerning the Prevention and Remedy of Environmental Damage and Environmental Pollution in Business Activity of General Mining,” Minister of Mines and Energy, Jakarta, 1995.

[4] The Republic of Indonesia, "Decree of the Minister of Mines and Energy Number 1453.k/29/MEM/2000 Concerning Technical Guidelines on Government Duties in General Mining,” Minister of Mines and Energy, Jakarta, 2000.

[5] The Republic of Indonesia, "State Minister of Environmental Regulation No. 08 Year of 2006 Concerning Guidance for Arranging Environmental Impact Assessment," State Minister of Environmental, Jakarta, 2006.

[6] P. A. Longley, M. F. Goodchild, D. J. Maguire and D. W. Rhind, "Geographical Information Systems, Volume 2, Management Issues and Applications,” 2nd Edition, John Wiley and Sons. Inc., New York, 1999.

[7] J. Delaney and K. Van Niel, "Geographical Information Systems: An Introduction,” 2nd Edition, Oxford University Press, Oxford, 2007.

[8] M. A. Ready, "Textbook of Remote Sensing and Geographical Information Systems,” 3rd Edition, BS Publications, Hyderabad, 2008.

[9] The Republic of Indonesia, "Government Regulation No 41/1999 on Air Pollution Control,” Jakarta, 1999.

[10] The Republic of Indonesia, "Decree of the State Minister of Environment No 48 of 1996 on Emission Standards for Noise Level,” Jakarta, 1996.

[11] The Republic of Indonesia, "Decree of the State Minister of Environment No 49 of 1996 on Standards for Vibration Level,” Jakarta, 1996.

[12] The Republic of Indonesia, "Decree of the State Minister of Environment No 13 of 1995 on Emission Standards for Stationary Source,” Jakarta, 1995. 
[13] The Republic of Indonesia, "Decree of the State Minister of Environment No 113 of 2003, Waste Water Standard for Coal Mining,” Jakarta, 2003.
[14] MCRMP, “Kamus Data,” Marine and Coastal Resources Management Project, 2005, p. 1. 